\title{
A holistic view of anesthesia-related neurotoxicity in children
}

This article was published in the following Dove Press journal:

Ambulatory Anesthesia

26 November 2015

Number of times this article has been viewed

\section{Nicola G Clausen \\ Tom G Hansen}

Department of Anesthesia and Intensive Care, Odense University Hospital, Odense, Denmark
Correspondence: Nicola G Clausen

Department of Anesthesia and Intensive Care, Odense University Hospital, Sdr Boulevard 29, 5000 Odense, Denmark Tel +45 4I I 2 868 I

Email nicola@nicola.dk
Introduction: Animal studies (including in nonhuman primates) have shown that most general anesthetics cause enhanced neuroapoptosis in the immature brain with subsequent long-term neurocognitive deficits later in life. Whether human neurons are equally affected is yet unknown, but a final answer to this issue is still pending. To date, most human studies within the field are of observational nature and the results are conflicting. Some studies indicate an association between exposure to anesthesia and surgery while others do not.

Objective: This review summarizes results from preclinical and observational studies. Controversies and challenges regarding the interpretation of these results are presented. Crucial aspects of neurocognitive safety during pediatric anesthesia and surgery are highlighted. International initiatives aiming to improve the safe conductance of pediatric anesthesia are introduced.

Conclusion: So far, anesthesia-related neurotoxicity in humans remains an area of concern but it cannot be completely excluded. Clinical practice should not be changed until there are definite proofs that anesthetic exposure causes neurocognitive impairment later in life. Withholding necessary and timely surgeries as a consequence of any such concerns could result in worse harm. Focus of current research should also be redirected to include other factors, than merely anesthetics and surgery, that influence the neurocognitive safety of children perioperatively.

Keywords: pediatric anesthesia, neurotoxicity, anesthesia safety, neurocognitive development

\section{Introduction}

In recent years, clinicians and parents have inquired whether anesthetic agents may be neurotoxic to the developing human brain. ${ }^{1-7}$ Animal studies (including in nonhuman primates) have shown that most general anesthetics (GA) cause enhanced neuroapoptosis with subsequent long-term neurocognitive deficits later in life. ${ }^{3,8-10}$ Some human cohort studies have indicated an association between anesthesia/surgery and adverse neurocognitive outcome, whereas other studies have not. ${ }^{11}$

\section{Objective}

This article summarizes results from preclinical and observational studies on anesthesia-related neurotoxicity. Controversies and challenges regarding the interpretation of these results are presented and aspects of neurocognitive safety during pediatric anesthesia highlighted.

\section{Background}

A variety of ion channels scattered throughout the central and peripheral nervous system are sensitive to GA. However, gamma-amino-butyric acid type $A\left(\mathrm{GABA}_{\mathrm{A}}\right)$ 
and glutamate receptors seem to play a pivotal role in facilitating the beneficial state of anesthesia. ${ }^{12}$

Anesthetics enhance inhibitory postsynaptic ion-channel activity by increasing glycine - and $\mathrm{GABA}_{\mathrm{A}}$ - receptors sensitivity to GABA. ${ }^{13,14}$ GABA is the predominant inhibitory neurotransmitter in the mature brain, ${ }^{15}$ facilitating the influx of chloride ions through opening of $\mathrm{GABA}_{\mathrm{A}}$ channels. This leads to hypersensibilization of the postsynaptic membrane and an overall reduced activity, which is observed as anxiolysis, sedation, amnesia, and anticonvulsion clinically. ${ }^{16}$ Propofol, volatile anesthetics, barbiturates, and benzodiazepines are examples of agents with these properties. In the immature brain, GABA has depolarizing properties, which facilitates the refinement of neuronal circuits early in postnatal development by acting on cell migration, synaptogenesis, DNA synthesis, and cell proliferation. ${ }^{17}$ This excitatory/inhibitory switch depends on the developmental upregulation of the potassium-chloride-cotransporter isoform 2 (KCC2) concordant with the downregulation of the potassium-chloride-cotransporter isoform 1 (NKCC1), which facilitates the net extrusion of intracellular anions in the immature neuron. While studies exposing newborn rats to intravenous anesthetics did not show any influence on the expression on $\mathrm{KCC} 2,{ }^{18}$ caspase- 3 activity was increased in brains of rats receiving sevoflurane without pretreatment with an NKCC1-blocker. ${ }^{19}$ The latter indicates cellular apoptosis as a response to sevoflurane exposure, mediated by GABAergic activation of $\mathrm{NKCC} 1$.

Anesthetics inhibit excitatory synaptic channel activity mediated by nicotinic acetylcholine, serotonin, and NMDA (N-methyl-D-aspartate)-sensitive glutamate receptors. ${ }^{20,21}$ Ketamine and nitrous oxide are examples of NMDA-receptor antagonizing drugs.

In the immature brain, exposure to nonphysiologic stressors, eg, drugs, hypoxia, ischemia, and hypoglycemia, at the time of peak synaptogenesis leads to neurodegeneration. ${ }^{22}$ In mice, this period occurs in the early postnatal period, but this period may continue from midgestation to young childhood in humans. ${ }^{23}$ Apoptosis of neurons is part of normal development. Anesthetics have been shown to enhance this process by mechanisms not yet fully understood - but most likely involved are the mitochondria-dependent (intrinsic) and death-receptor mediated (extrinsic) caspase pathways. ${ }^{24,25}$ Neurodevelopment seems to be highly dependent on external stimuli and neuronal trafficking. Hence, exaggerated apoptosis is believed to follow after interference with interneuronal signaling pathways and/or an imbalance between inhibitory and excitatory stimuli. ${ }^{26}$

\section{Animal studies}

A growing number of animal studies has demonstrated increased neuronal apoptosis following exposure to GA. ${ }^{8,9,26-29}$ In one of the landmark studies, Ikonomidou ${ }^{9}$ exposed rats to NMDA antagonists on day 7 postnatally (PD7). Neurons showed signs of excessive apoptosis, preferentially in the frontal and parietal cortex as well as in the thalamus. ${ }^{30}$ Additional studies have shown that the extent of apoptosis seems to vary between brain areas, suggesting a regional difference in susceptibility to neurotoxins. ${ }^{31,32}$ Cellular structures other than neurons seem to be affected; exposure to volatile anesthetics has been shown to result in altered dendritic spine architecture. ${ }^{33,34}$ Neonatal rhesus macaques exposed to isoflurane showed extensive apoptosis of oligodendrocytes compared to astrocytes, microglia, and interstitial neurons. ${ }^{35}$ How these histopathologic changes relate to neurocognition remains to be resolved, since there is yet no evidence of a

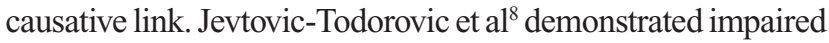
learning in rats in the Morris water maze following exposure to midazolam, isoflurane, and nitrous oxide in combination. Most disturbingly, this impaired learning persisted into adulthood. Similar results have been obtained in various animal species, including rhesus monkeys. ${ }^{36}$ In a recent study, rhesus monkeys of both sexes were subject to sevoflurane anesthesia for 4 hours on postnatal days 6-10, and again 14 and 28 days later. ${ }^{37}$ At the age of 6 months, exposed and nonexposed monkeys were tested for their emotional reactivity toward intrusion of a human (human intruder paradigm). The frequency of anxiety-related behavior was higher in exposed than unexposed monkeys, which the authors speculate might reflect long-term effects of anesthesia. In contrast, another study on cynomolgus monkeys, exposing 6-day-old male animals to a similar sevoflurane anesthesia, did not affect their behavior tested by the "holding cage method" when they were tested at 3 and 7 months. Nor were the animals affected in learning or memory. ${ }^{38}$ Although the studies investigated two different subspecies of monkeys, it is not apparent as to why their results point in opposite directions. Overall, it is unknown how any of these findings correlate to the human pediatric population.

\section{Observational human studies}

So far, a number of observational studies have been published. Some of these studies argue against any association between early exposure to anesthesia and surgery and negative neurocognitive outcome.

In a Dutch study, academic performance and cognition was assessed in 1,143 twin pairs identified in the Young Netherlands' Twin Register. ${ }^{39}$ Information on exposure to 
unspecified surgery and anesthesia was collected by mailed surveys to the parents. Overall, lower equal standardized educational attainment scores and more cognitive problems/ inattention as rated by teachers were found among exposed than unexposed twins. Interestingly, the 71 monozygotic twin pairs discordant for exposure showed no difference in performance between the exposed and the unexposed twin. Two Danish nationwide cohort studies comprising the complete birth cohort from 1986 to 1990 assessed, during adolescence, the academic performance of children who underwent surgery for pyloric stenosis repair before 3 months of age $\mathrm{e}^{40}$ and inguinal hernia repair before 1 year of age ${ }^{41}$ respectively. In both studies, the outcome of the exposed children was compared to that of a 5\% randomly selected group of unexposed children within the same cohorts. The average mean test score did not differ between children exposed to pyloric stenosis repair and nonexposed controls (mean difference: -0.01 ; 95\% confidence interval [CI]: 0.09-0.08 lower). The same tendency was seen for children undergoing inguinal hernia repair: their estimated mean of test scores was 0.04 below that of the control group (95\% CI: 0.01-0.09). However, in both studies, rates of nonattainment were slightly higher among exposed versus nonexposed individuals: after hernia repair the odds ratio for not obtaining test scores was $1.18(95 \%$ CI: $1.04-1.35)$; in the pyloric stenosis repair group odds ratio was 1.37 (95\% CI: 1.11-1.68). Academic performance in children who had spinal anesthesia for inguinal hernia repair, circumcision, and pyloric stenosis repair was compared to nonexposed controls matched by grade, sex, year of testing, and socioeconomic status. On elementary school level, exposure to spinal anesthesia and surgery did not increase the odds for having very poor academic achievement. ${ }^{42}$

On the other hand, some observational studies do suggest adverse neurocognitive outcome following anesthesia and surgical exposure.

In Olmstead County, Minnesota, all children born from 1976 to 1982 were included in a retrospective study investigating the association between general anesthesia for all types of surgeries before the age of 4 and learning disability (LD). Multiple exposures were found to be a significant risk factor for $\mathrm{LD}$, the incidence among exposed individuals at age 19 years being 35.1\% (95\% CI: 26.2\%-42.9\%) compared to $20.0 \%$ (95\% CI: $18.8 \%-21.3 \%)$ for children not exposed at all. ${ }^{43}$ Using the same birth cohort, the same group compared the need for individual educational programs and the results in tests of cognition and achievement between children exposed to any kind of surgery before the age of 2 and unexposed controls. Controls were matched for maternal level of education, birth weight, gestational age, and sex, all factors knowingly associated with LD and age.

Again, multiple exposures increased the risk of LD (hazard ratio: 2.16 ; 95\% CI: $1.35-3.46$ ) as well as the need for individual educational programs (hazard ratio: 4.76 ; $95 \% \mathrm{CI}$ : 2.48-9.12). ${ }^{44}$ In a third study within the same birth cohort, the authors investigated the association between exposure to surgery and GA and diagnosis of attention deficit hyperactivity disorder (ADHD): multiple exposures were associated with an increased risk of being diagnosed with ADHD (hazard ratio: $1.95 ; 95 \% \mathrm{CI}: 1.03-3.71) .^{45}$

Enrollees in the New York State Medicaid program born from 1999 to 2001 were included in a retrospective cohort analysis. Compared to controls, frequency-matched in age (in months) but not in any other parameters, children undergoing GA for inguinal hernia repair before the age of 3 were more than twice as likely to be diagnosed with a developmental or behavioral disorder (hazard ratio: 2.3 ; 95\% CI: $1.3-4.1$ ). ${ }^{46}$ Controls were randomly selected among children in the same birth cohort and may have been exposed to anesthesia and any other surgery but inguinal hernia repair. In a retrospective twin-sibling study based on children born from 1999 to 2005 and enrolled in the same Medicaid program, exposure to GA for any kind of surgery before the age of 3 increased the risk of behavioral disorders by 1.6 (95\% CI: $1.4-1.8)$. Interestingly, the risk increased from 1.1 (95\% CI: 0.8-1.4) for one exposure to 2.9 (94\% CI: $2.5,3.1)$ for two, and 4.0 $(95 \%$ CI: $3.5,4.5)$ for three or more exposures. ${ }^{47}$

The Western Australian Pregnancy Cohort (the Raine Study) contains information on 2,868 subjects born between 1989 and $1992 .{ }^{48}$ Until birth, demographic and medical data were collected on pregnant women who had good English language skills, had planned to deliver in hospital, and expected to stay in Western Australia for the decade to come. Postnatal data were based on parent reporting, such as information on exposures and nonexposures to anesthesia and surgery. Based on this information, children exposed to GA for all types of surgery before the age of 3 were tested neuropsychologically at the age of 10, and their results were compared to outcome in unexposed children within the same cohort. Exposure was associated with an increased risk of poor performance in language (risk ratio: 1.87; 95\% CI: 1.12-2.64) and cognition (risk ratio: 1.69; 95\% CI: 1.3-2.53). This association persisted with a single exposure to anesthesia. ${ }^{48}$

In Iowa, Block et $\mathrm{al}^{49}$ compared composite scores in the Iowa test of basic skills and education between the general population and 185 children previously exposed to anesthesia and surgery for circumcision, pyloric stenosis, 
or inguinal hernia repair with/without orchidopexy before the age of 1. Exposed children were identified from the department of anesthesia's billing records, and data were based on medical records and retrieved after written consent from parents. Within the cohort, a subgroup of 75 children at high risk for cognitive dysfunction (eg, due to central nervous system disorders) were recorded separately. Compared to the general Iowa population, exposed children had very low achievement test scores (below the fifth percentile), both overall and within the "high-risk cohort". 49

In a recently conducted matched-control study, Backeljauw et al $^{50}$ assessed academic achievements in the Oral and Written Language scales (OWLS) and Wechsler Performance IQ Intelligence Scale for Children. A total of 53 children with an existing MRI (magnetic resonance imaging) scan of the cerebrum and previous exposure to general anesthesia for all kinds of surgery before the age of 4 were compared to 53 controls identified in the same cross-sectional MRI database. Controls were chosen if they were found neurologically healthy on examination and had no history of neurological or psychiatric illness, head trauma, previous or current LD, or prematurity. Furthermore, they were matched on age, sex, socioeconomic status, and left- or right-handedness. Besides other surgical procedures, all exposed children underwent at least one ear-nose-throat intervention. Whereas mean cognitive test scores were found to be within population norms, the exposed group presented significantly lower scores for performance IQ and OWLS listening comprehension. Furthermore, there was a decrease in gray matter in distinct cortical areas that have previously been associated with impaired cognition and language skills. Due to the retrospective study design, no conclusions about causality can be made. Notably, the frequencies of both the Wechsler performance IQ and OWLS listening comprehension scores for exposed children follow a Gaussian distribution, as opposed to unexposed controls. Although exposed children are matched according to relevant parameters, this could be explained by systematic differences between the study groups, confounding the outcome under investigation. Furthermore, any association between exposure and outcome might be overestimated due to the high occurrence of ear-nose-throat procedures in the exposed group, since this group of patients often presents with impaired language skills and cognition problems.

Table 1 gives an overview of selected observational studies. $^{51-54}$

\section{Ongoing clinical studies}

Three clinical studies are currently in progress: the Pediatric Anesthesia and Neurodevelopment Assessment Multicenter study (http://www.kidspandastudy.org/index.html/), the Mayo Safety for Kids study, ${ }^{55}$ and the General Anaesthesia compared to Spinal Anaesthesia (GAS) study. ${ }^{56,57}$ While these studies have the advantage of being prospective and based on cohorts selected for the purpose, they are timeconsuming and expensive. Table 2 summarizes the studies' objectives, study populations, and outcomes.

\section{Interpretation of current knowledge: challenges and pitfalls}

The discrepancy between results in preclinical and observational studies can, to some extent, be explained by many of the impediments of the study designs employed and will now be considered.

Results from animal studies cannot by default be transferred to a human population for the following, but assumingly not exhaustive, reasons:

1. The course of an anesthetic is different in animals compared to a human setting since vital signs and end tidal levels of inhalational gases are rarely monitored, neither are changes in blood glucose, acid-base status, body temperature, and partial pressures of oxygen and carbon dioxide. Furthermore, airways are often not secured and unsupported, spontaneous respiration is maintained, especially in small animals using high concentrations of oxygen. These variables may each and/or in combination influence perfusion and oxygenation of the cerebrum and hence have an impact on neuronal cell function. As a consequence, the isolated effect of the anesthetics cannot be demonstrated.

2. Doses of anesthetics administered and durations of exposures are not analogous to those usually used in clinical pediatric practice; for instance, Paule et a ${ }^{136}$ found impaired learning in rhesus monkeys after 24 hours of anesthesia induced with up to $50 \mathrm{mg} / \mathrm{kg}$ of ketamine. Furthermore, the routes of administration often vary due to the reduced size of the animals, rendering pharmacokinetics and pharmacodynamics of anesthetics unpredictable.

3. Great effort has been put into translating developmental stages of the animal central nervous system into the human corollary (http://www.translatingtime.net), creating a theoretical model based on mathematical algorithms.$^{58}$ However, these do not account for inter- and intraindividual variations. 


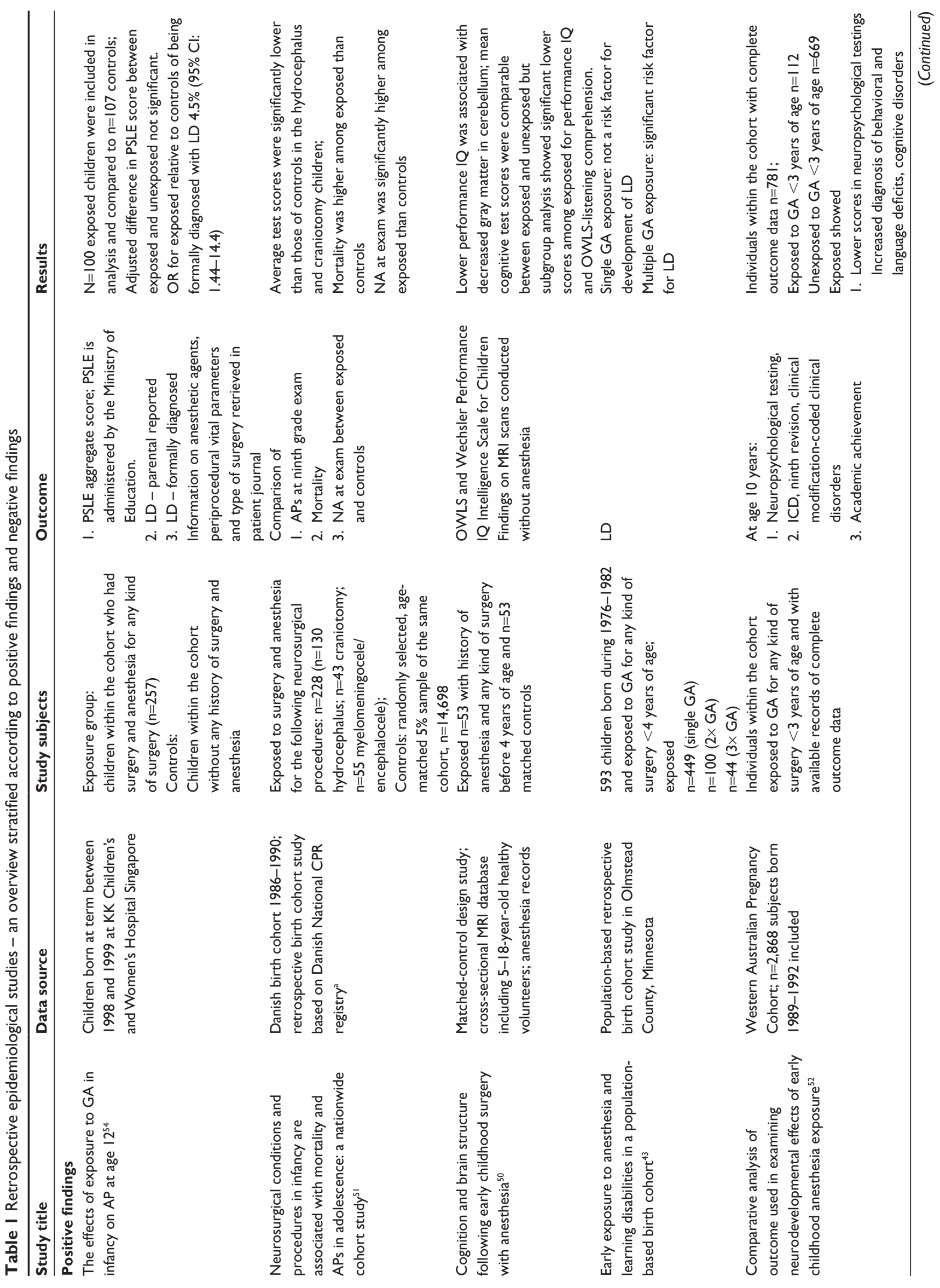




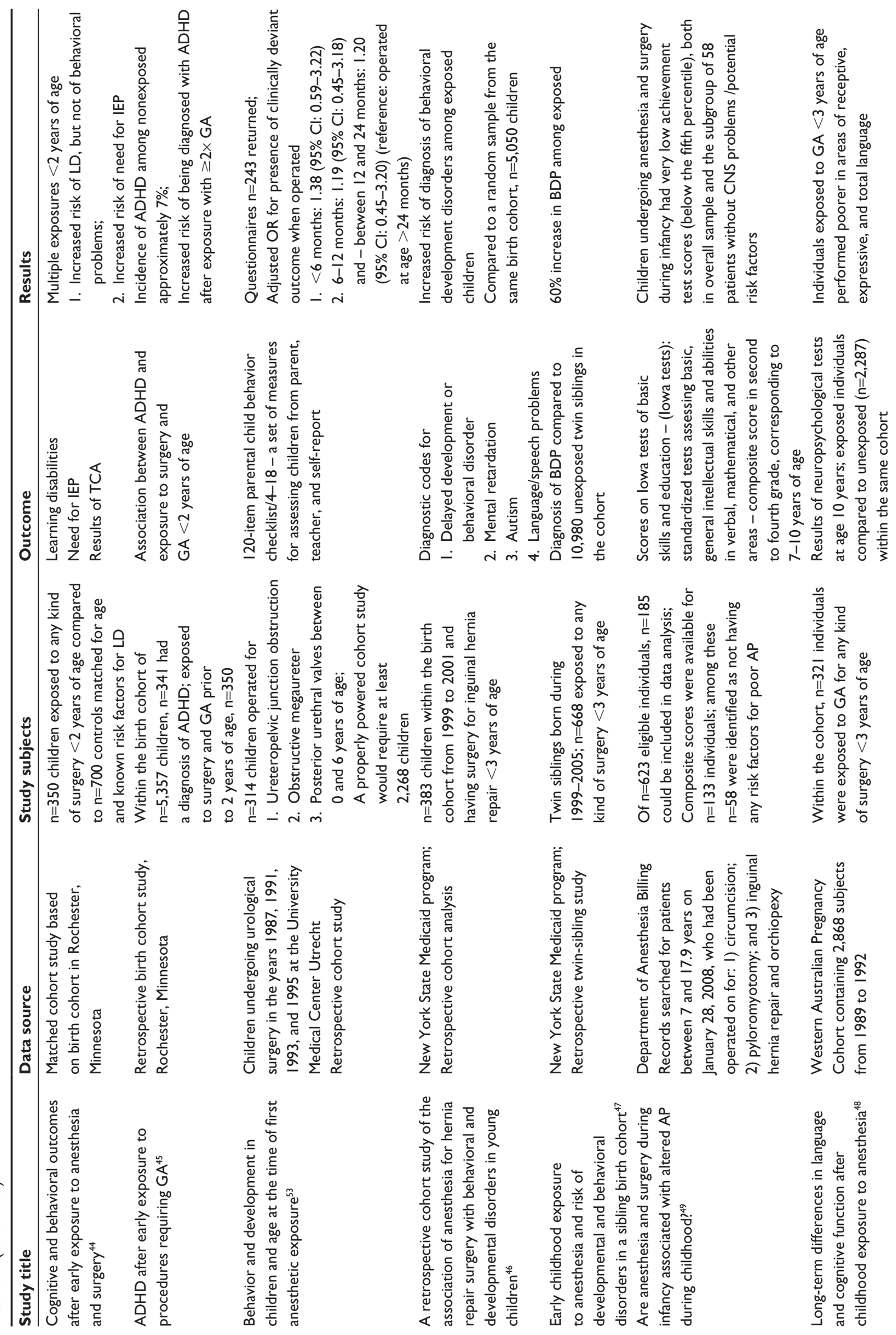



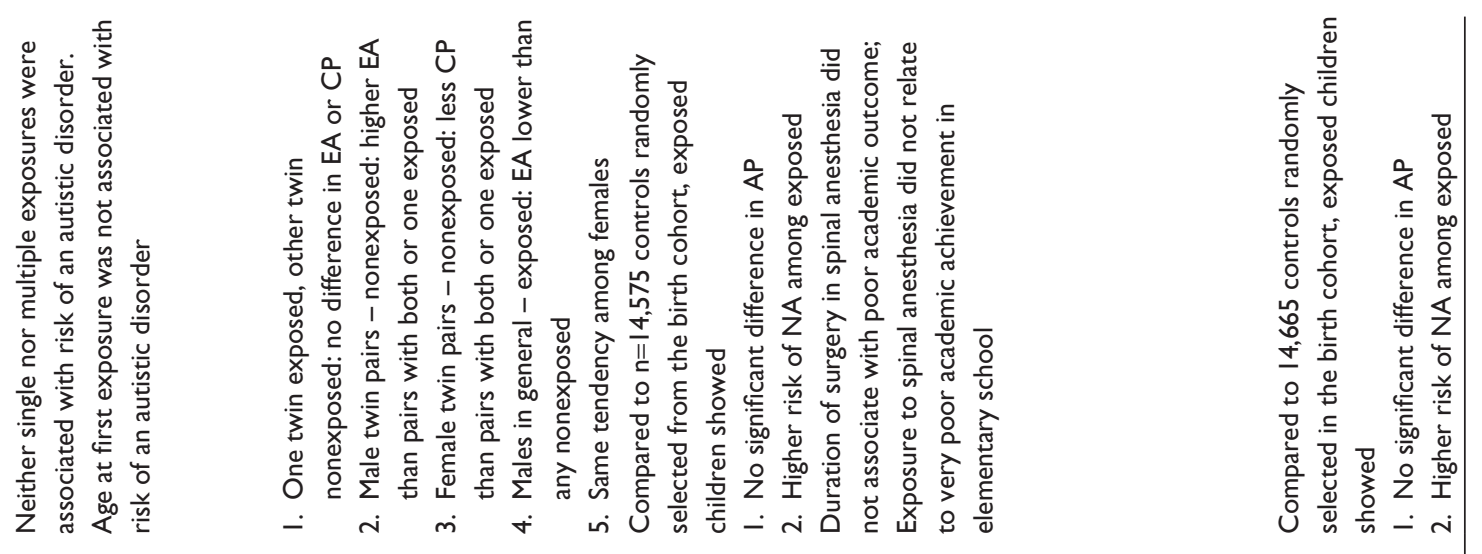

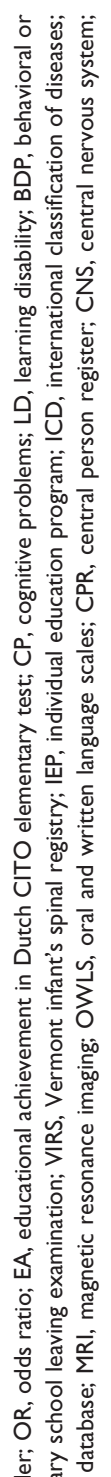

守希。
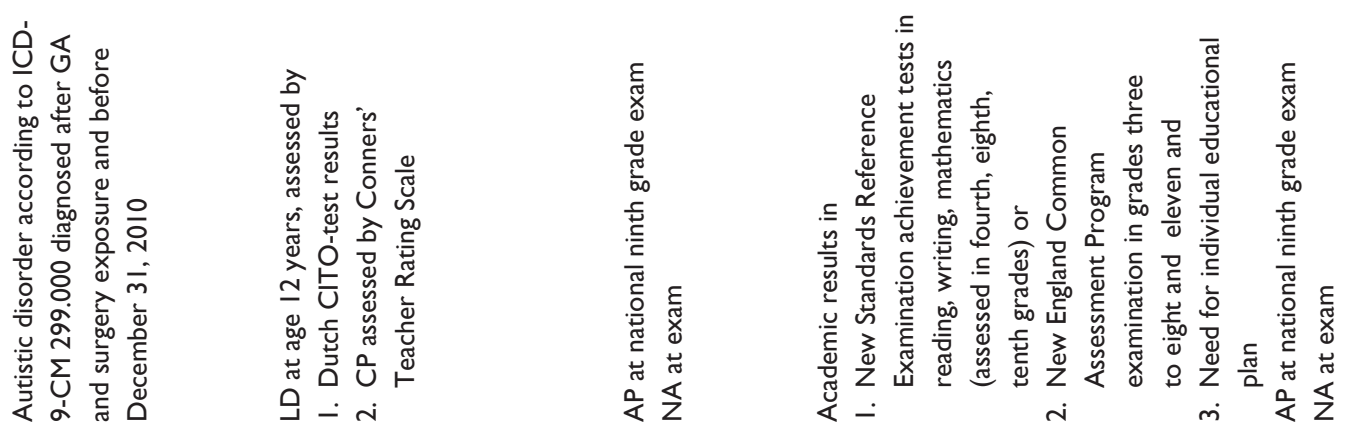

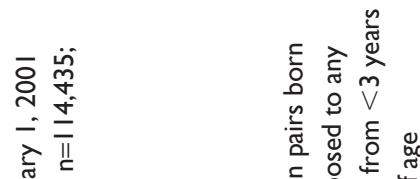

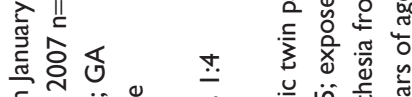

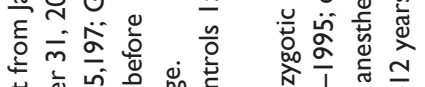

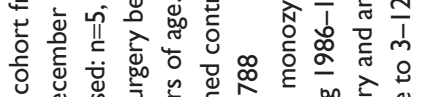

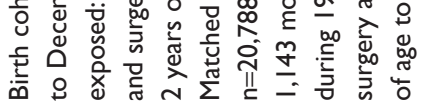
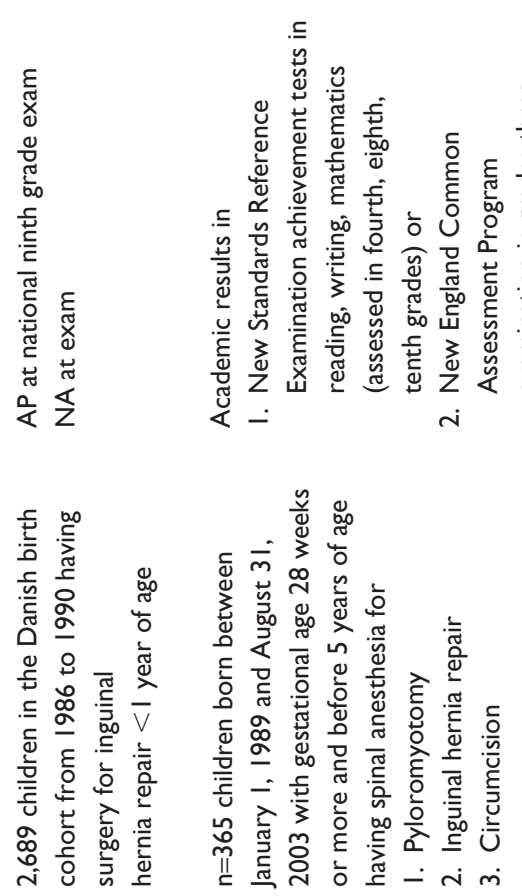

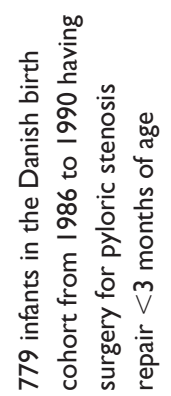
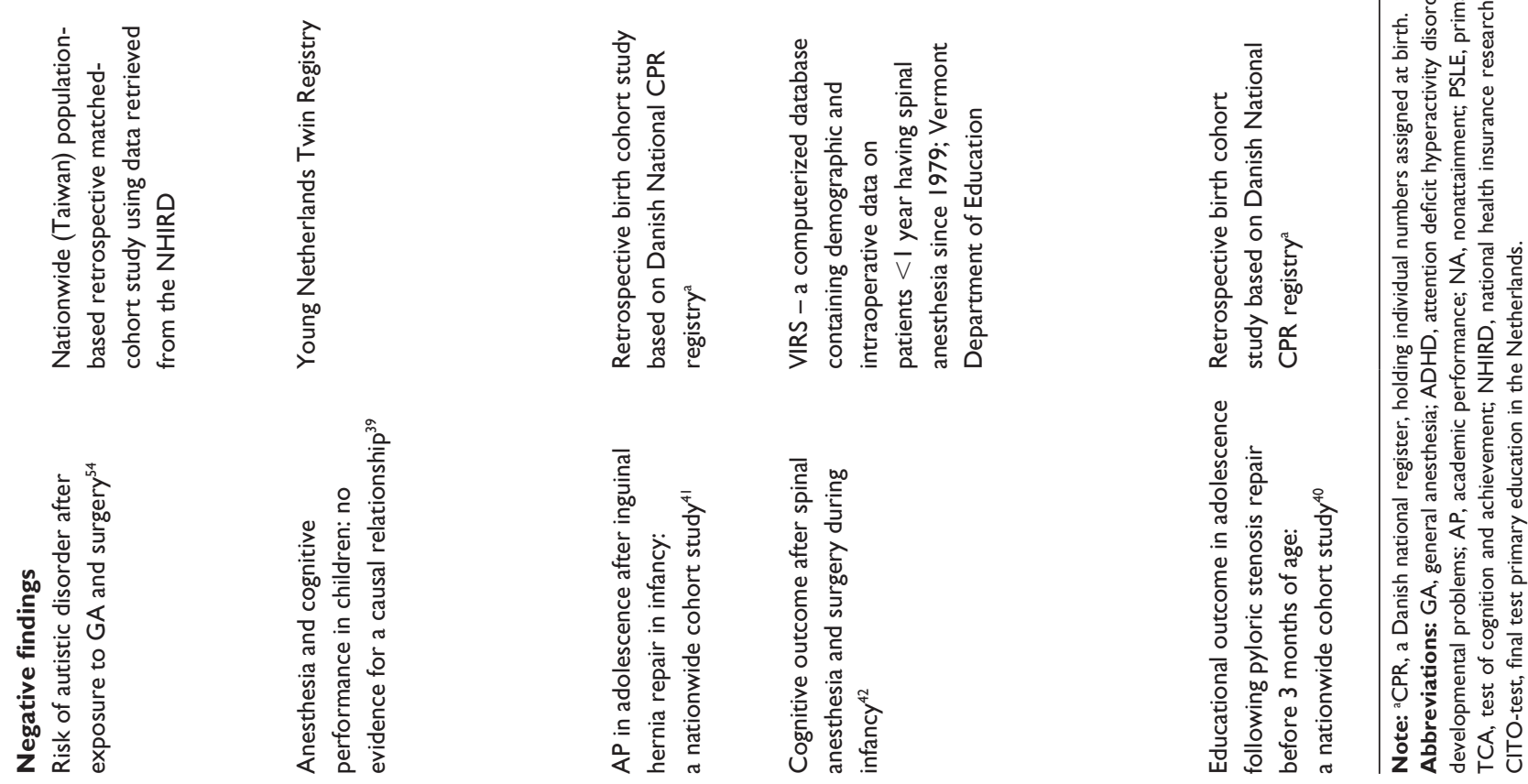
Table 2 Ongoing prospective trials

\begin{tabular}{|c|c|c|c|}
\hline Study name & Design & Cohort & Primary outcome \\
\hline GAS a study & Multisite randomized controlled trial & $\begin{array}{l}\text { Newborns randomized to spinal or GA for } \\
\text { inguinal hernia repair }\end{array}$ & $\begin{array}{l}\text { IQ score at age } 2 \text { and } 5 \text { years in } \\
\text { WPPSI-III }\end{array}$ \\
\hline MASK study & $\begin{array}{l}\text { Cohort study, retrospective regarding } \\
\text { exposure, prospective regarding } \\
\text { outcome }\end{array}$ & $\begin{array}{l}\text { Children born between } 1994 \text { and } 2007 \text { exposed to } \\
\text { single or multiple GA before } 3 \text { years of age compared } \\
\text { to controls from the same cohort }\end{array}$ & $\begin{array}{l}\text { Results in single 4-hour } \\
\text { neuropsychological test battery }\end{array}$ \\
\hline PANDA study & Ambidirectional cohort study & $\begin{array}{l}\text { Sibling exposed to GA before } 3 \text { years of age for } \\
\text { inguinal hernia repair compared to nonexposed sibling }\end{array}$ & $\begin{array}{l}\text { WASI-II scores and NEPSY II scores } \\
\text { between } 8 \text { and I } 5 \text { years of age }\end{array}$ \\
\hline
\end{tabular}

Note: ${ }^{\mathrm{A}} \mathrm{A}$ multisite randomized controlled trial comparing regional and general anesthesia for effects on neurodevelopmental outcome and apnea in infants.

Abbreviations: GA, general anesthesia; WPPSI-III, Wechsler Preschool and Primary Scale of Intelligence - third edition; MASK, Mayo Safety for Kids; PANDA, Pediatric Anesthesia and Neurodevelopmental Assessment; WASI-II, Wechsler Abbreviated Scale for Intelligence - second edition; NEPSY II, A Developmental Neuropsychological Assessment - second edition; GAS, General Anaesthesia compared to Spinal Anaesthesia.

4. In an animal setting, anesthesia is conducted solely for the purpose of the experiment. Hence, anesthesia is conducted without any concurrent surgical trauma or other types of insults. There are data suggesting that anesthetics under such conditions might be neuroprotective rather than neurotoxic. McAuliffe et $\mathrm{al}^{59}$ exposed 9-day-old mice to isoflurane, desflurane, sevoflurane, or room air for 3 hours. The next day the animals had 60 minutes of hypoxia-ischemia. Histological sections did not show any difference between the groups regarding neuronal injury. But those animals preconditioned with a volatile agent performed better in behavioral testing than animals preconditioned with room air alone. With regard to some parts of the tests, exposed animals even performed equal to the sham group not exposed at all. ${ }^{59}$ Similarly, both short-term structural and long-term functional neuroprotection has been demonstrated when volatile anesthetics were administered to 10-day-old mice after induction of brain ischemia. ${ }^{60}$ In a randomized study on piglets having cardiac pulmonary bypass surgery, postoperative neurologic outcome was improved among animals anesthetized with desflurane compared to animals allocated to the administration of fentanyl-droperidol. ${ }^{61}$ This exemplifies anesthetic neuroprotection in a setting, where the trauma of surgery is superimposed to a state of reduced cerebral blood flow. The mechanism behind the neuroprotective properties of volatile anesthetics is not fully understood. However, in an animal setting, volatile anesthetics have been shown to reduce cerebral blood flow less than intravenous sedatives. ${ }^{62}$ Since the underlying condition, the impact of surgery itself, and the potential neurotoxic effects of anesthetics are intertwined in a human setting, observational studies are prone to "confounding by indication". This adds to the overall lack of control of confounders.
5. It is unknown how both short-term and long-term toxic damage to neurons will present themselves clinically. Any consequence is likely to depend on both the age and neurodevelopmental stage at exposure and at time of follow-up. Individual variations in neurodevelopmental progress cannot be taken into account. Based on findings in animal studies, it is assumed that brain areas responsible for learning and memory are affected intensively by anesthetics. Hence, learning difficulties, academic performance in standardized examinations, and behavioral disorders have been used as estimates of function in these areas. However, outcomes assessed in observational studies in order to investigate neurotoxicity were constructed for other purposes: school grades aim to reflect certain skills achieved through comprehension of teaching and learning contents communicated both verbally and in writing; codes of behavioral and psychiatric disorders intend to apprehend pathological conditions, which is also true for neuropsychological test batteries. It is assumed, not known, that they function as acceptable measures of clinically relevant neurotoxic effects. Moreover, many of these tests are interrelated. Increasing the number of tests used in a study increases the risk for type 1 statistical error.

6. Cohort studies based on administrative cohorts are sensitive to selection; the included individuals might not be representative of overall populations, thus weakening the generalizability of results. Similarly, losses to follow-up might under- or overestimate an association under investigation. The persons lost to death and migration might have one or more features in common that enhance or mitigate an association.

\section{Discussion}

If anesthesia-related neurotoxicity exists in humans, $2,7,63-72$ many additional answers are urgently needed: Who is at risk? 
Is this an age-associated phenomenon? Which dosages and which agents cause greatest damage? What is the impact of surgery and diagnosis? How does any such potential damage present itself? Which study designs are most likely to answer these questions?

Observational studies are retrospective and based on data that were selected for other purposes, ie, administration. While this does make data more prone to selection bias and in some instances reduces the generalizability of results, they are still valuable and feasible. An observational study design will never demonstrate a causative association, but can rather illustrate which issues are important. This requires either a large cohort or a strong association between exposure and outcome. The inconsistent results of observational data so far suggest that an association between anesthesia and surgery and neurocognitive impairment is either minor or hidden behind confounding factors. Multiple studies have shown the underlying disease and/or surgery, prematurity, sex, and parental level of education to have higher impact on outcome than anesthesia itself. ${ }^{51}$ McCann and Schouten $^{73}$ have recently reviewed the impact of blood pressure and perioperative cerebral perfusion on neurodevelopment in ex-prematures and infants. Infants have less cerebral autoregulatory reserve rendering them more vulnerable to hypotension, and prone to hypocapnia-induced cerebral ischemia - both these factors may contribute to the development of hypoxic-ischemic encephalopathy. In its mild form, hypoxic-ischemic encephalopathy is characterized by postoperative irritability, poor feeding, excessive crying or sleepiness, or even seizures in more severe cases.

For future research, it must be taken into account that many factors other than exposure to anesthetic drugs contribute to impaired neurodevelopment in young children exposed to anesthesia and surgery. Introducing "The $10 \mathrm{~N}$ 's", Weiss et $\mathrm{al}^{74}$ emphasizes ten factors of importance for the safe conductance of anesthesia: absence of pain and fear, normotension, normocardia, normooxemia, normocarbia, normothermia, normovolemia, normonatremia, and normoglycemia. This multifactorial approach is the cornerstone of the safe anesthesia for every tot initiative (SAFETOTS). The initiative aims to increase focus on safe conductance of pediatric anesthesia and define the safe use of anesthetics in the pediatric population (http://www.safetots.org). Within this framework, two studies are currently in progress: Anaesthesia PRactice In Children Observational Trial (APRICOT) and NEonate-Children sTudy of Anaesthesia pRactice IN Europe (NECTARINE).
APRICOT, a prospective multicenter observational study, investigates the incidence of severe critical events in children undergoing anesthesia in Europe. From April 1, 2014 to December 31, 2014, participating centers in Europe registered variables concerning the pre-, peri- and postanesthesia process. Data are currently being analyzed and results are expected in 2016 (ClinicalTrials.gov website: NCT01878760).

As an extension of the APRICOT study, NECTARINE, a prospective, observational multicenter audit, will provide information on morbidity and mortality related to neonatal anesthesia. Over a 12-week observation period, beginning on March 1, 2016, data on 5,000 patients in European centers will be registered (ClinicalTrials.gov website: NCT02350348).

According to a recent web-based survey among practicing European anesthetists, ${ }^{75}$ the majority consider neurotoxicity an important topic. Two-third of the anesthetists reported that they had changed their clinical practice in an attempt to reduce any potential harm. Based on current knowledge, a change in practice is unfounded and should be balanced against the risks related to withholding necessary surgery.

\section{Summary}

Histologic changes in neurons and long-term neurocognitive impairments due to exposure to anesthetics are well documented in animal studies. Results from human observational studies are less clear and, due to inconsistent study designs and varying measures of outcome, difficult to compare. Anesthesia-related neurotoxicity can neither be excluded nor verified based on these findings, and the significance of this issue for the children requiring surgery and anesthesia worldwide remains unknown at present. A change in clinical practice cannot be recommended at this point.

Results from the few ongoing randomized trials are still awaited and will add to current knowledge rather than completely resolve this complex issue. Future studies will broaden their search for factors other than anesthetics that have the potential of impairing neurodevelopment of infants.

\section{Disclosure}

The authors report no conflicts of interest in this work.

\section{References}

1. Nemergut ME, Aganga D, Flick RP. Anesthetic neurotoxicity: what to tell the parents? Paediatr Anaesth. 2014;24(1):120-126.

2. Hansen TG. Anesthesia-related neurotoxicity and the developing animal brain is not a significant problem in children. Paediatr Anaesth 2015;25(1):65-72. 
3. Jevtovic-Todorovic V, Absalom AR, Blomgren K, et al. Anaesthetic neurotoxicity and neuroplasticity: an expert group report and statement based on the BJA Salzburg seminar. Br J Anaesth. 2013; 111(2):143-151.

4. Vutskits L, Davis PJ, Hansen TG. Anesthetics and the developing brain: time for a change in practice? A pro/con debate. Paediatr Anaesth. 2012;22(10):973-980.

5. Psaty BM, Platt R, Altman RB. Neurotoxicity of generic anesthesia agents in infants and children: an orphan research question in search of a sponsor. JAMA. 2015;313(15):1515-1516.

6. Hupp JR. Pediatric anesthesia-concerns about neurotoxicity. J Oral Maxillofac Surg. 2015;73(6):1021-1022.

7. Warner DO, Flick RP. Effects of anesthesia and surgery on the developing brain: problem solved? Paediatr Anaesth. 2015;25(4): 435-436.

8. Jevtovic-Todorovic V, Hartman RE, Izumi Y, et al. Early exposure to common anesthetic agents causes widespread neurodegeneration in the developing rat brain and persistent learning deficits. J Neurosci. 2003; 23(3):876-882.

9. Ikonomidou C. Triggers of apoptosis in the immature brain. Brain Dev. 2009;31(7):488-492.

10. Vutskits L. Review article: general anesthesia: a gateway to modulate synapse formation and neural plasticity? Anesth Analg. 2012; 115(5):1174-1182.

11. Rappaport BA, Suresh S, Hertz S, Evers AS, Orser BA. Anesthetic neurotoxicity - clinical implications of animal models. $N$ Engl J Med. 2015;372(9):796-797.

12. Campagna JA, Miller KW, Forman SA. Mechanisms of actions of inhaled anesthetics. N Engl J Med. 2003;348(21):2110-2124.

13. Solt K, Forman SA. Correlating the clinical actions and molecular mechanisms of general anesthetics. Curr Opin Anaesthesiol. 2007; 20(4):300-306.

14. Lee V, Maguire J. The impact of tonic GABAA receptor-mediated inhibition on neuronal excitability varies across brain region and cell type. Front Neural Circuits. 2014;8:3.

15. Nishikawa K, Kubo K, Obata H, Yanagawa Y, Saito S. The influence of manipulations to alter ambient GABA concentrations on the hypnotic and immobilizing actions produced by sevoflurane, propofol, and midazolam. Neuropharmacology. 2011;61(1-2):172-180.

16. Lee JH, Zhang J, Wei L, Yu SP. Neurodevelopmental implications of the general anesthesia in neonate and infants. Exp Neurol. Epub 2015 Apr 8

17. Cellot G, Cherubini E. Functional role of ambient GABA in refining neuronal circuits early in postnatal development. Front Neural Circuits. 2013;7:136

18. Lacoh CM, Bodogan T, Kaila K, Fiumelli H, Vutskits L. General anaesthetics do not impair developmental expression of the KCC2 potassium-chloride cotransporter in neonatal rats during the brain growth spurt. Br J Anaesth. 2013;110(Suppl 1):i10-i18.

19. Edwards DA, Shah HP, Cao W, Gravenstein N, Seubert CN, Martynyuk AE. Bumetanide alleviates epileptogenic and neurotoxic effects of sevoflurane in neonatal rat brain. Anesthesiology. 2010;112(3): 567-575.

20. Mellon RD, Simone AF, Rappaport BA. Use of anesthetic agents in neonates and young children. Anesth Analg. 2007;104(3): 509-520.

21. Loepke AW, Soriano SG. An assessment of the effects of general anesthetics on developing brain structure and neurocognitive function. Anesth Analg. 2008;106(6):1681-1707.

22. Soriano SG, Anand KJ. Anesthetics and brain toxicity. Curr Opin Anaesthesiol. 2005;18(3):293-297.

23. Creeley CE, Olney JW. The young: neuroapoptosis induced by anesthetics and what to do about it. Anesth Analg. 2010;110(2):442-448.

24. Blaylock M, Engelhardt T, Bissonnette B. Fundamentals of neuronal apoptosis relevant to pediatric anesthesia. Paediatr Anaesth. 2010; 20(5):383-395.
25. Yon JH, Daniel-Johnson J, Carter LB, Jevtovic-Todorovic V. Anesthesia induces neuronal cell death in the developing rat brain via the intrinsic and extrinsic apoptotic pathways. Neuroscience. 2005; 135(3):815-827.

26. Patel P, Sun L. Update on neonatal anesthetic neurotoxicity: insight into molecular mechanisms and relevance to humans. Anesthesiology. 2009;110(4):703-708.

27. Wang C, Sadovova N, Fu X, et al. The role of the N-methyl-D-aspartate receptor in ketamine-induced apoptosis in rat forebrain culture. Neuroscience. 2005;132(4):967-977.

28. Sanders RD, Xu J, Shu Y, Fidalgo A, Ma D, Maze M. General anesthetics induce apoptotic neurodegeneration in the neonatal rat spinal cord. Anesth Analg. 2008;106(6):1708-1711.

29. Istaphanous GK, Howard J, Nan X, et al. Comparison of the neuroapoptotic properties of equipotent anesthetic concentrations of desflurane, isoflurane, or sevoflurane in neonatal mice. Anesthesiology. 2011; 114(3):578-587.

30. Ikonomidou $\mathrm{C}$, Bosch F, Miksa M, et al. Blockade of NMDA receptors and apoptotic neurodegeneration in the developing brain. Science. 1999; 283(5398):70-74.

31. Stratmann G, Sall JW, May LD, Loepke AW, Lee MT. Beyond anesthetic properties: the effects of isoflurane on brain cell death, neurogenesis, and long-term neurocognitive function. Anesth Analg. 2010; 110(2):431-437.

32. DiGruccio MR, Joksimovic S, Joksovic PM, et al. Hyperexcitability of rat thalamocortical networks after exposure to general anesthesia during brain development. J Neurosci. 2015;35(4):1481-1492.

33. Briner A, De Roo M, Dayer A, Muller D, Habre W, Vutskits L. Volatile anesthetics rapidly increase dendritic spine density in the rat medial prefrontal cortex during synaptogenesis. Anesthesiology. 2010; 112(3):546-556.

34. Qiu L, Zhu C, Bodogan T, et al. Acute and long-term effects of brief sevoflurane anesthesia during the early postnatal period in rats. Toxicol Sci. Epub 2015 Sep 30 .

35. Brambrink AM, Back SA, Riddle A, et al. Isoflurane-induced apoptosis of oligodendrocytes in the neonatal primate brain. Ann Neurol. 2012; 72(4):525-535

36. Paule MG, Li M, Allen RR, et al. Ketamine anesthesia during the first week of life can cause long-lasting cognitive deficits in rhesus monkeys. Neurotoxicol Teratol. 2011;33(2):220-230.

37. Raper J, Alvarado MC, Murphy KL, Baxter MG. Multiple anesthetic exposure in infant monkeys alters emotional reactivity to an acute stressor. Anesthesiology. Epub 2015 Sep 2.

38. Zhou L, Wang Z, Zhou H, et al. Neonatal exposure to sevoflurane may not cause learning and memory deficits and behavioral abnormality in the childhood of Cynomolgus monkeys. Sci Rep. 2015;5:11145

39. Bartels M, Althoff RR, Boomsma DI. Anesthesia and cognitive performance in children: no evidence for a causal relationship. Twin Res Hum Genet. 2009;12(3):246-253.

40. Hansen TG, Pedersen JK, Henneberg SW, Morton NS, Christensen K. Educational outcome in adolescence following pyloric stenosis repair before 3 months of age: a nationwide cohort study. Paediatr Anaesth. 2013;23(10):883-890.

41. Hansen TG, Pedersen JK, Henneberg SW, et al. Academic performance in adolescence after inguinal hernia repair in infancy: a nationwide cohort study. Anesthesiology. 2011;114(5):1076-1085.

42. Williams RK, Black IH, Howard DB, et al. Cognitive outcome after spinal anesthesia and surgery during infancy. Anesth Analg. 2014; 119(3):651-660.

43. Wilder RT, Flick RP, Sprung J, et al. Early exposure to anesthesia and learning disabilities in a population-based birth cohort. Anesthesiology. 2009;110(4):796-804.

44. Flick RP, Katusic SK, Colligan RC, et al. Cognitive and behavioral outcomes after early exposure to anesthesia and surgery. Pediatrics. 2011;128(5):e1053-e1061. 
45. Sprung J, Flick RP, Katusic SK, et al. Attention-deficit/hyperactivity disorder after early exposure to procedures requiring general anesthesia. Mayo Clin Proc. 2012;87(2):120-129.

46. DiMaggio C, Sun LS, Kakavouli A, Byrne MW, Li G. A retrospective cohort study of the association of anesthesia and hernia repair surgery with behavioral and developmental disorders in young children. J Neurosurg Anesthesiol. 2009;21(4):286-291.

47. DiMaggio C, Sun LS, Li G. Early childhood exposure to anesthesia and risk of developmental and behavioral disorders in a sibling birth cohort. Anesth Analg. 2011;113(5):1143-1151.

48. Ing C, Dimaggio C, Whitehouse A, et al. Long-term differences in language and cognitive function after childhood exposure to anesthesia. Pediatrics. 2012;130(3):e476-e485.

49. Block RI, Thomas JJ, Bayman EO, Choi JY, Kimble KK, Todd MM. Are anesthesia and surgery during infancy associated with altered academic performance during childhood? Anesthesiology. 2012;117(3):494-503.

50. Backeljauw B, Holland SK, Altaye M, Loepke AW. Cognition and brain structure following early childhood surgery with anesthesia. Pediatrics. 2015;136(1):e1-e12.

51. Hansen TG, Pedersen JK, Henneberg SW, Morton NS, Christensen K. Neurosurgical conditions and procedures in infancy are associated with mortality and academic performances in adolescence: a nationwide cohort study. Paediatr Anaesth. 2015;25(2):186-192.

52. Ing CH, DiMaggio CJ, Malacova E, et al. Comparative analysis of outcome measures used in examining neurodevelopmental effects of early childhood anesthesia exposure. Anesthesiology. 2014; 120(6):1319-1332.

53. Kalkman CJ, Peelen L, Moons KG, et al. Behavior and development in children and age at the time of first anesthetic exposure. Anesthesiology. 2009;110(4):805-812.

54. Ko WR, Huang JY, Chiang YC, et al. Risk of autistic disorder after exposure to general anaesthesia and surgery: a nationwide, retrospective matched cohort study. Eur J Anaesthesiol. 2015;32(5):303-310.

55. Gleich SJ, Flick R, Hu D, et al. Neurodevelopment of children exposed to anesthesia: design of the mayo anesthesia safety in kids (MASK) study. Contemp Clin Trials. 2015;41:45-54.

56. Davidson A, McCann ME, Morton N. Anesthesia neurotoxicity in neonates: the need for clinical research. Anesth Analg. 2007; 105(3):881-882.

57. Davidson AJ, Morton NS, Arnup SJ, et al. Apnea after awake regional and general anesthesia in infants: the general anesthesia compared to spinal anesthesia study-comparing apnea and neurodevelopmental outcomes, a randomized controlled trial. Anesthesiology. 2015;123: 38-54.

58. Workman AD, Charvet CJ, Clancy B, Darlington RB, Finlay BL. Modeling transformations of neurodevelopmental sequences across mammalian species. J Neurosci. 2013;33(17):7368-7383.

59. McAuliffe JJ, Loepke AW, Miles L, Joseph B, Hughes E, Vorhees CV. Desflurane, isoflurane, and sevoflurane provide limited neuroprotection against neonatal hypoxia-ischemia in a delayed preconditioning paradigm. Anesthesiology. 2009;111(3):533-546.
60. Lin EP, Miles L, Hughes EA, et al. A combination of mild hypothermia and sevoflurane affords long-term protection in a modified neonatal mouse model of cerebral hypoxia-ischemia. Anesth Analg. 2014; 119(5):1158-1173.

61. Loepke AW, Priestley MA, Schultz SE, McCann J, Golden J, Kurth CD. Desflurane improves neurologic outcome after low-flow cardiopulmonary bypass in newborn pigs. Anesthesiology. 2002; 97(6):1521-1527.

62. Vutskits L. Cerebral blood flow in the neonate. Paediatr Anaesth. 2014;24(1):22-29.

63. Sinner B, Becke K, Engelhard K. General anaesthetics and the developing brain: an overview. Anaesthesia. 2014;69(9):1009-1022.

64. Lin EP, Soriano SG, Loepke AW. Anesthetic neurotoxicity. Anesthesiol Clin. 2014;32(1):133-155.

65. Jevtovic-Todorovic V. Pediatric anesthesia neurotoxicity: an overview of the 2011 SmartTots panel. Anesth Analg. 2011;113(5):965-968.

66. Davidson AJ, Becke K, de Graaff J, et al. Anesthesia and the developing brain: a way forward for clinical research. Paediatr Anaesth. 2015; 25(5):447-452.

67. Byrne MW, Casale P, Garzon M, et al. Pediatric surgeons and anesthesiologists expand the dialogue on the neurotoxicity question, rationale for early and delayed surgeries, and practice changes while awaiting definitive evidence. J Neurosurg Anesthesiol. 2014;26(4):391-395.

68. Wise-Faberowski L, Quinonez ZA, Hammer GB. Anesthesia and the developing brain: relevance to the pediatric cardiac surgery. Brain Sci. 2014;4(2):295-310.

69. Laub DR Jr, Williams RK. Neonatal anesthesia neurotoxicity: a review for cleft and craniofacial surgeons. Cleft Palate Craniofac J. 2014 52(4):494-498.

70. Sun LS. Introduction to "Anesthesia and Neurodevelopment in Children": a supplement from the Fourth PANDA Symposium. J Neurosurg Anesthesiol. 2014;26(4):343.

71. Batista HMT, Pinheiro WR, de Menezes Silveira GB, et al. Learning disorders related to exposure to general anesthetics in children. Neurol Neurosci. 2015;1:1-8.

72. Duarte S, Saraiva A, Machado HS. Anesthetic neurotoxicity to the fragile young brain: where do we stand? J Pregnancy Child Health. 2015;2(1000):e121.

73. McCann ME, Schouten AN. Beyond survival; influences of blood pressure, cerebral perfusion and anesthesia on neurodevelopment. Paediatr Anaesth. 2014;24(1):68-73.

74. Weiss M, Vutskits L, Hansen TG, Engelhardt T. Safe anesthesia for every tot - the SAFETOTS initiative. Curr Opin Anaesthesiol. 2015 28(3):302-307.

75. Weber F, van Beek S, Scoones G. Potential neurotoxicity of anaesthetic drugs in young children - who cares? A survey among European anaesthetists. Minerva Anestesiol. Epub 2015 Sep 3.
Ambulatory Anesthesia

\section{Publish your work in this journal}

Ambulatory Anesthesia is an international, peer reviewed, open access journal publishing articles that address all aspects of ambulatory anesthesia practice, in particular: anesthetic techniques, sedation and safety practices, pharmacokinetics, preoperative evaluation, analgesia interventions, regulatory and compliance issues, postoperative recovery,

\section{Dovepress}

patient satisfaction, administrative topics, and cost analysis themes. The manuscript management system is completely online and includes a very quick and fair peer review system, which is all easy to use. Visit http://www.dovepress.com/testimonials.php to read real quotes from published authors. 